Research Article

\title{
Fuzzy Control System for Predicting The Quality of Thermally Processed Raw Milk
}

\author{
Büşra UZUN ${ }^{a}$ (D), Novruz Allahverdi ${ }^{a} *$ \\ ${ }^{a}$ Computer Engineering Department, KTO Karatay University, Konya/Türkiye
}

\begin{tabular}{|c|c|}
\hline ARTICLE INFO & ABSTRACT \\
\hline $\begin{array}{l}\text { Article history: } \\
\text { Received 09 August } 2021 \\
\text { Accepted 13 September } 2021 \\
\text { Keywords: } \\
\text { Fuzzy Control Systems } \\
\text { Fuzzy Logic } \\
\text { Heat treatment } \\
\text { Fuzzy Logic Algorithm } \\
\text { Microbial load } \\
\text { pH value }\end{array}$ & $\begin{array}{l}\text { Milk, which has a very important place in human nutrition, can be harmful in terms of } \\
\text { human health when it is not produced, stored, processed, and necessary controls are } \\
\text { performed under hygienic conditions. Even if raw milk contains a small number of } \\
\text { bacteria, it is degraded in a very short time after the milking by the effects of } \\
\text { microorganisms transmitted from the environment in various ways and constitutes the } \\
\text { potential source of many pathogens that cause diseases in humans. } \\
\text { Milk proteins contain essential amino acids that cannot be synthesized by the human } \\
\text { body and must be taken from the outside. The microorganism load of milk is one of the } \\
\text { most important indicators in determining milk quality and determining the hygienic } \\
\text { properties of milk in the process from raw milk production to consumption. Fuzzy logic, } \\
\text { which is frequently used in the solution of problems that occur in uncertain situations } \\
\text { such as quality assessment in recent years, is one of the artificial intelligence methods. } \\
\text { In this study, it was aimed to develop a fuzzy logic-based decision support system aimed } \\
\text { at predicting the deterioration of heat-treated raw milk. As the subject of this project, it } \\
\text { was developed to determine whether the milk produced in troops, farms and cooperatives } \\
\text { is spoiled before the milk goes from production households to businesses. }\end{array}$ \\
\hline
\end{tabular}

This is an open access article under the CC BY-SA 4.0 license. (https://creativecommons.org/licenses/by-sa/4.0/)

\section{Introduction}

Milk is a basic food that should be consumed at any age for healthy growth and development. However, milk is quickly exposed to external factors and can easily bad. For this reason, it must be treated with heat before it is consumed. UHT (ultra-high temperature) plays an important role in this process as the most advanced milk processing technology used worldwide since 1961. Due to the technology, the first condition for ultra-pasteurized milk production is the use of quality milk. Milk taken from farms, unions and cooperatives is delivered directly to the dairy plant as part of the cold chain. Raw milk is subjected to a thorough quality check before it is accepted for production. Quality Control Components

- Antibiotic test.

- Total dry matter

- Somatic cell counts
- Acidity

The milk found suitable as a result of the tests goes to the dairy and is sent to the raw milk storage tanks. Unwanted foreign substances may have been added to the milk. These could be impurities, large bacteria, skin rashes, stones, soil, oil, hair, fertilizer. Facilities first clean the milk of these foreign substances. Then the milk smells you do not like may be barnyard, manure or feed odors[18]. Air deodorizer make these odors vanish. Butter is standardized on milk brought from different plants. Ultra pasteurization is used to clean the milk from foreign microorganisms. In this process, the milk is heated to 135 150 degrees for 2-6 seconds and quickly cooled to room temperature. The nutritional value of the milk is retained in this way. The milk is poured into 6-layer cartons, light and airtight in a sterile environment. Thus, it is ready for 
consumption.

Today, every system is automated, and the world's systems are trying to make more and more precise technology available. Therefore, to ensure efficiency and accuracy, fuzzy control system has been developed to make the milk canning system an adaptive controllable system. Fuzzy logic systems are more efficient and accurate because of the variable environment. The input and output variables change depending on the situation. The values of the output variables are obtained according to the change in the input values using the rule base of the fuzzy logic system.

In 1965, the first article on fuzzy logic, titled "Fuzzy Sets," was by Zadeh. Zadeh stated that people's mentality often involves fuzzy expressions in which there is no certainty. He drew attention to the need to consider intermediate values as well as certain distinctions, such as " 0 " and " 1 " in classical logic, and stated that events are displayed with a certain degree in the interval $[0,1,19]$.

In recent years, methods based on fuzzy logic have been successfully applied in the fields of agriculture and animal husbandry, as well as in the fields of engineering, medicine and biology in cases of uncertainty and objectivity. Fuzzy expert systems and decision support systems created using fuzzy logic in the field of medicine are often used for decision making in the diagnosis and evaluation of serious diseases such as cancer and tumors. The purpose of this study is to develop a decision support system based on fuzzy logic that aims to divide raw milk into three quality classes: high quality, medium quality, and low quality. Here we used MATLAB software, which provides an interface for our work.

\section{Materials and Method 2.1 Fuzzy Logic}

Azerbaijan scientist Lotfi A. Zadeh stated that for fuzzy (ambiguous) situations, which cannot be defined by probability distributions, mathematics is needed [1, 10, 11]. Zadeh wrote the first paper on fuzzy logic, titled "Fuzzy Sets," in 1965 [1]. Zadeh stated that human thinking often involves fuzzy expressions that are not exact. In addition to certain distinctions such as " 0 " and "1" in the classical literature. Logic, intermediate values are also included.

Drew attention to the need to consider this and stated that events are displayed with a degree in the range $[0,1]$ $[2,3]$. With the advent of fuzzy logic theory, significant improvements have been made, especially in the processing of verbal data in human thinking. Fuzzy systems act as a bridge when moving from verbal data to numerical data [3, 4]. Classical methods can be used when dealing with accurate numerical data, but classical methods do not give healthy results when dealing with problems arising under uncertainty [4].

Modern technology, especially through various programs based on artificial intelligence, allows people to mimic their perceptual skills with computers and learn to a certain extent. Artificial intelligence methods such as fuzzy logic, artificial neural networks, expert systems and genetic algorithms are successfully used in various disciplines, especially in engineering and medicine [5].

In recent years, methods based on fuzzy logic have been successfully applied in the fields of agriculture and animal husbandry, as well as in the fields of engineering, medicine and biology, where uncertainty and objectivity exist. Fuzzy expert systems and decision support systems created using fuzzy logic in the field of medicine are often used for decision making in the diagnosis and evaluation of serious diseases such as cancer and tumors [6].

Evaluation of rapid test methods and HPLC technique in antibiotic residue analysis in raw milks was examined in the study [7]. Milk microbiology and additives have been examined in the literature [8]. Microbiological analysis and somatic cell counts in raw milk from farms of Sao Paulo State was made at [9].

Comparison of artificial neural network and K-means for clustering dairy cattle was made in [12] the work examined the microbiological quality of Karin oil, traditionally produced in Turkey [13].

This article was designed to determine if the milk produced by unions, farms and cooperatives is spoiled before it reaches the plants. In developing the fuzzy logic system, a system with four inputs and one output was designed. Fuzzy systems are knowledge-based systems created by structuring fuzzy "if-then" rules and providing a systematic process for transforming a nonlinear function into a knowledge base[20]. Through the theory of fuzzy logic, expert knowledge is converted into computer systems using "if-then" rules. In the fuzzification process, certain intervals have been given for each input, which have been divided into 4 groups. The same process is performed on the output and the whole system is defuzzyficated. In a system with fuzzy input as the output of the system, a certain output was obtained both linguistically and numerically.

\subsection{Definition of Fuzzy Logic Rules}

It is aimed at getting a percentage value of the risk of milk spoilage from the system, which has four inputs: thermal temperature, milk $\mathrm{pH}$ value, microbial load and production date (Figure 1).

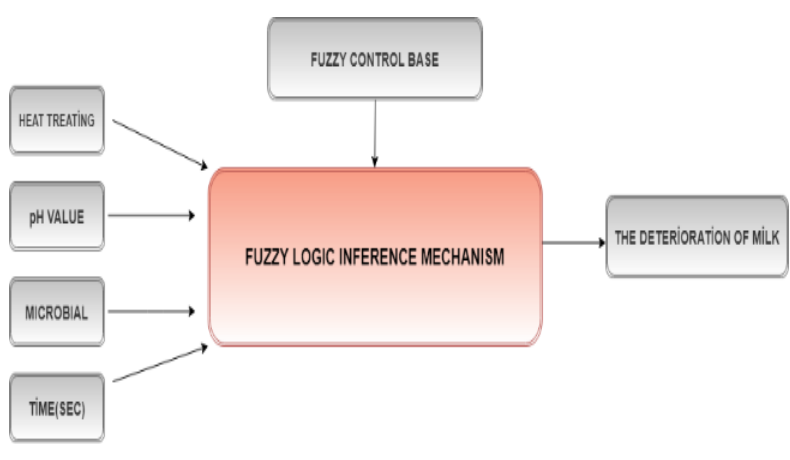

Figure 1. Structure of the fuzzy logic system

The minimum and maximum range of input and output values used in the system is shown in Table 2.1. Table 2.2 shows the output value ranges of the projected system. 


\begin{tabular}{|l|c|c|c|}
\hline $\begin{array}{l}\text { Variable } \\
\text { Names: }\end{array}$ & LOW & MEDIUM & HIGH \\
\hline Time(sec.) & $2-6$ & $4-20$ & $15-20$ \\
\hline pH Value & $6,2-6,6$ & $6,5-6,8$ & $\mathrm{x}>7$ \\
\hline $\begin{array}{l}\text { Microbial } \\
\text { Load }\end{array}$ & $\mathrm{x}<10^{4}$ & $\begin{array}{l}\mathrm{x}=>5 * 10^{4} \\
\mathrm{x}<=10^{5}\end{array}$ & $\mathrm{x}>10^{5}$ \\
\hline
\end{tabular}

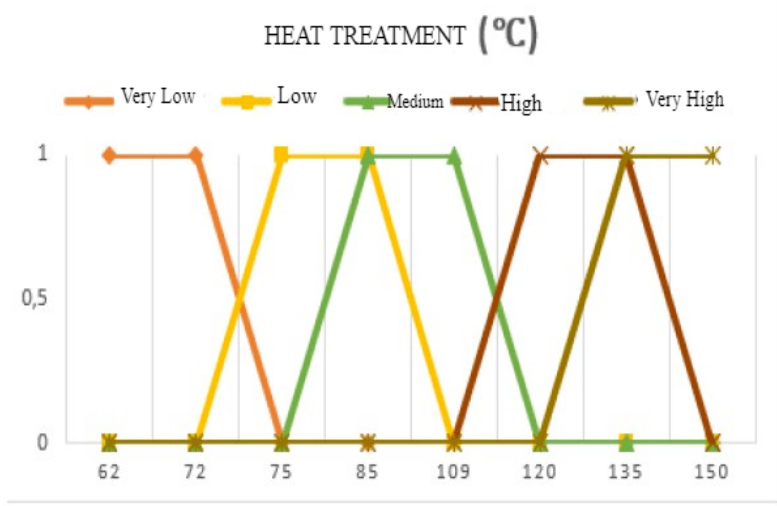

Figure 2. Graphical Display of Fuzzy Thermal Temperature Inputs.

\subsection{2. $\mathrm{pH}$ value}

A sample delivered to the raw milk laboratory is first tested for the presence of antibiotics using the antibiotic kit. The presence of antibiotics is determined according to the lines indicated on the kit. Milk with antibiotics is not accepted. The $\mathrm{pH}$ of normal, fresh milk is between 6,6 and $6,8 \mathrm{pH}$ between 6,0 and 7,5. Milk with a $\mathrm{pH}$ above 6,8 presumably contains substances such as mastitis or neutralizing soda that has been added to the milk. Oral milk or excessive acidity has been observed in milk with a $\mathrm{pH}$ below 6,5 .

The $\mathrm{pH}$ value is also divided into 3 members. Our initial membership is low, where a numerical value range of 5, 3 to 6,5 is considered appropriate. The research used was the determination of milk cut between 5, 3 and 5,5 milk pH. If the $\mathrm{pH}$ value is 5,7 the clotting determination is used when heating that milk. If the $\mathrm{pH}$ value is, 6,3 this milk is given an initial acidification determination. Graphical view of the $\mathrm{pH}$ values is shown in the Figure 3 .

According to the decision made by the examiner, a low membership definition of milk between 5,3 and $6,5 \mathrm{pH}$ is given. As a second membership, it was decided to place the milk in the normal fresh milk class and give it a second name. As a final membership, the definition of milk with mastitis was used for values with $\mathrm{pH}$ above 6,8 . Figure 4 shows how to enter the duration of milk's stay in heat treatment to Matlab application. 


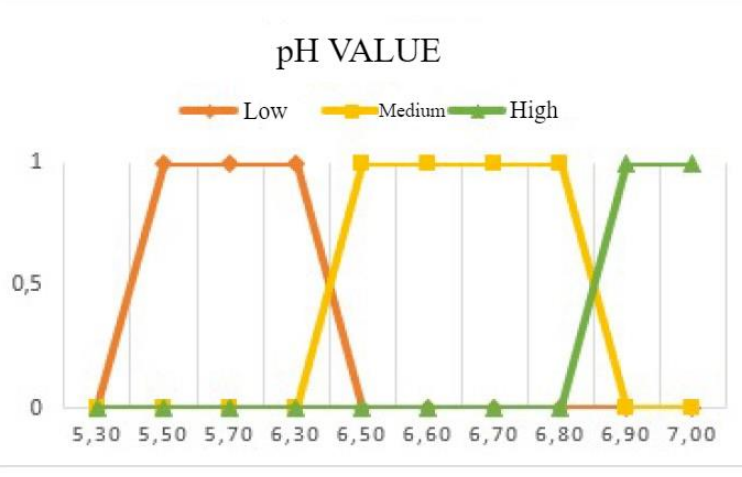

Figure 3. Graphical Display of Fuzzy pH Values

\subsubsection{Microbial Load}

In addition to the physical, chemical and sensory quality of raw milk, its biological quality is also an important factor. Since the milk reaches the oral cavity of the pup directly from the mammary gland, a microbial contamination of the milk from the environment is practically not possible [7].

However, while milk is secreted, it can be contaminated from the mammary tissue and epithelial cells in the mammary gland duct. In this study, the physical, chemical, sensory and biological quality of raw milk was emphasized in terms of human health and product quality[17]. In Fig. 2.4 , the entry of the rules of the microbial load values in the Matlab application is shown.

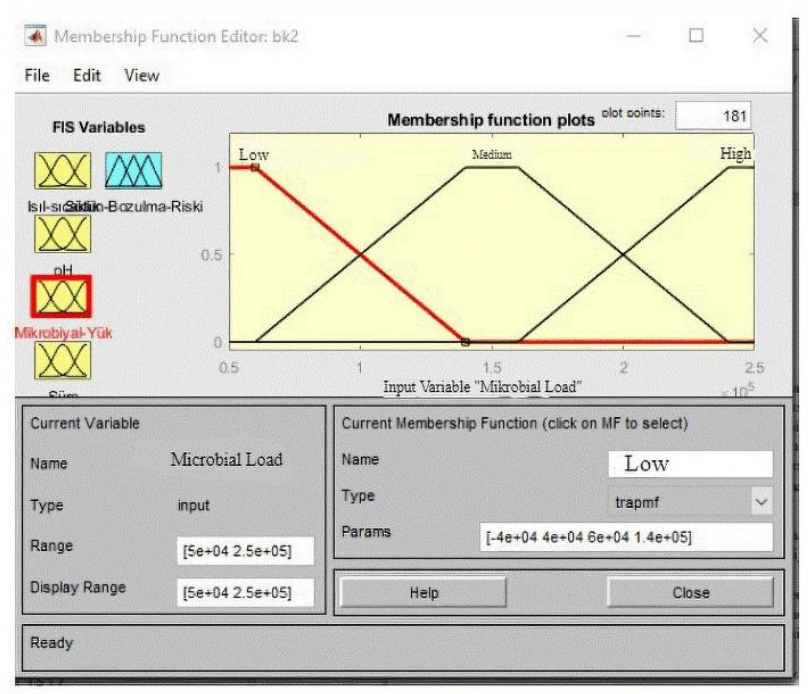

Figure 4. Mikrobial Load in Matlab application

\subsubsection{Heat Treatment Time}

In line with the expert's decision, he stated that this entry is very important since the time the milk is kept at thermal temperature is closely related to the deterioration of the milk.

For precision, the thermal-temperature time- relationship was divided into 3 members. The first subscription time was set to be between 2 and 6 seconds low.

The second membership was between 4 and 20 seconds, and the third was between 15 and 30 seconds. In Figure 5, it is shown to enter the values of the residence time of the milk in the heat treatment to the Matlab application.

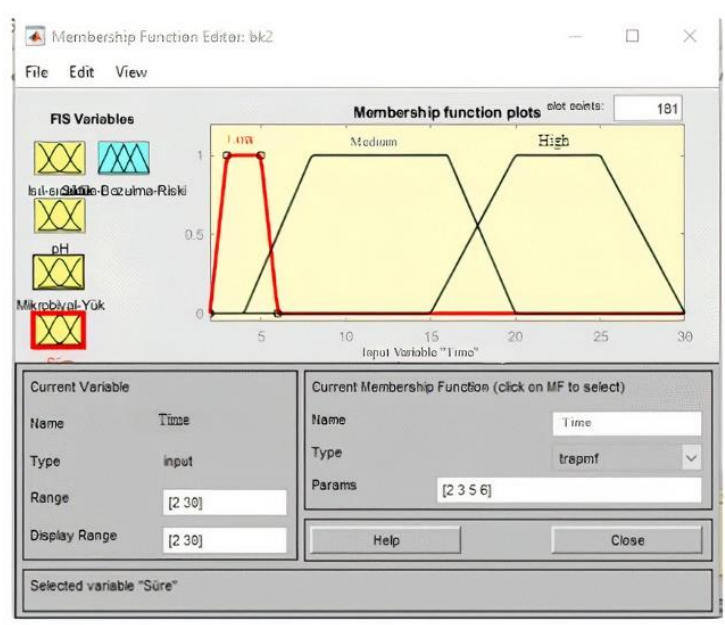

Figure 5. Time Values in Matlab Application

\subsubsection{Risk of Milk Deterioration}

The risk class of milk deterioration was created as the exit from the entrances taken from the fuzzy control project designed. This created output value is divided into 3 memberships. There is a $0 \%$ chance that these memberships will not spoil the first milk is not between $36 \%$ and $36 \%$.

As a second membership, the risk of milk deterioration is between $33 \%$ and $68 \%$, and the last membership is the milk degradation membership.

\section{Metrics Used and Experiment Result}

\subsection{Determining the Rule Table of the System}

How many rules will be in the rule table of the created fuzzy system is calculated with a formula provided by the fuzzy logic. If we apply this formula in this system, each entry gives us the result of multiplying the membership group numbers. There should be $3 \times 3 \times 3 \times 5=135$ rules in our rule table. Considering all the possibilities that may occur in this rule table, it is necessary to remove the impossible possibilities from the table and create the rule table at this stage. 125 rules approved by the expert were taken as a basis from the 135-rule table of the application, which gives the risk of spoilage of milk as a percentage. 


\subsection{Implementation of the System with MATLAB Fuzzy Toolbox}

Matlab R2015b-Academicuse version Fuzzy Toolbox tool was used as the interface required to run the designed system.

\subsection{Fuzzyfication (Blurring)}

The blurring algorithm in this project is Mamdani fuzzification algorithm. It is the most widely used algorithm in the world that operates on fuzzy sets using the Min-Max structure [14, 15]. Min is the method means taking the value with the smallest membership degree from the values at the junction of two fuzzy memberships. Max is the method in which the values with the highest membership degree are selected in the membership formed by the combination of two fuzzy memberships.

\subsection{Clarification (Defuzzyfication)}

After the fuzzy input values are subjected to all rules, a fuzzy inference value is generated for each input. The process of converting these fuzzy values back into sharp values, such as input values, is called defuzzification[16]. The most used clarification methods are:

- Maximum Membership Policy (Max-Membership)

- Center-of-gravity/area method,

- Weighted average

- Average Maximum Membership method (Mean Max membership)

In this study, the centroid clarification method was used by default. In this part, the system is tested using the mom clarification method. After the change is made to see the difference of the clarification methods, the differences can be observed as the output when the system works with View + Rules.

\section{Conclusion}

In this study, the centroid rinse (defuzzyfication) method was used as the default. In this part, the system was tested by the mother's rinse method. Once a change is made to see the difference in rinse methods, differences can be observed as a conclusion when the system works with View and Rules.

Fuzzy control rules were used in the design developed. A food engineer determined the fuzzy control rules used, and the accuracy of the design output was verified by a food engineer. During the testing phase, 10 samples were simulated in MATLAB software and the results were discussed. As a result of the discussions, it was determined that 8 of the 10 samples identified by the expert gave correct results.

Example:

Classification of Entries:

- Temperature: Low

- pH Value: Low

- Microbial Load: Low

- Time: Low

- Risk of Milk Deterioration: High

At a heat temperature of 80 degrees Celsius for 5 seconds, there is a risk of deterioration in milk with a $\mathrm{pH}$ of 6.2 and a microbial charge of $1.3 e-05$ and $74.2 \%$ (Figure $6)$.

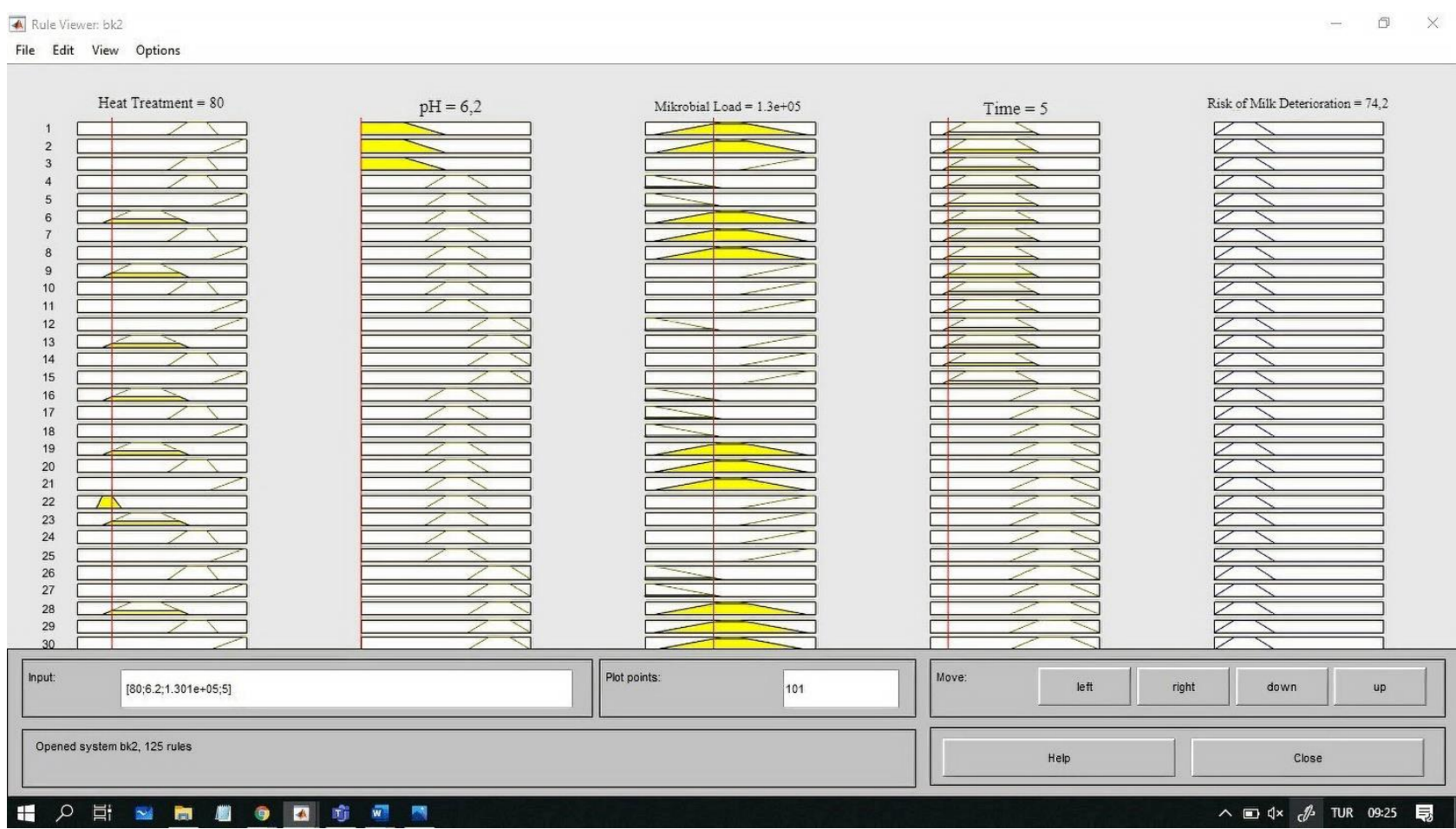

Figure 6. Output of the Sample Question 


\section{References}

[1] Goguen, J. A. (1973). LA Zadeh. Fuzzy sets. Information and control, vol. 8 (1965), pp. 338-353.LA Zadeh. Similarity relations and fuzzy orderings. Information sciences, vol. 3 (1971), pp. 177-200. The Journal of Symbolic Logic, 38(4), 656-657.

[2] Onur, S. (2016). Automation software development for milk measuring and tracking station (Master's thesis, Balıkesir Üniversitesi Fen Bilimleri Enstitüsü).

[3] DİLER, A., \& BARAN, A. (2014). Determination of some quality characteristics of raw milk samples taken from small scale farm tank milks around Hinıs district of Erzurum.. Alinteri Journal of Agriculture Science, 26(1), 18-24.

[4] Torlak, E., Gokmen, M., Gurbuz, U., Kiztanir, B., \& Işik, M. K. (2012). Evaluation of rapid test methods and HPLC technique in antibiotic residue analysis in raw milk. Ataturk University Journal of Veterinary Sciences, 7(2), 105-111.

[5] AKILLI, A., ATIL, H., \& Kesenkas, H. (2014). Fuzzy logic approach in raw milk quality assessment. Journal of Kafkas University Faculty of Veterinary Medicine, 20(2), 223-229.

[6] Demirci, M. (2000). Milk Microbiology and Additives. Milk and Dairy Products Symposium Proceedings Book, Rebel Publishing, first edition, 37 55.

[7] Fagundes, H., Pompeu, L. B., Corassin, C. H., \& de Oliveira, C. A. F. (2011). Microbiological analysis and somatic cell counts in raw milk from farms of So Paulo State, Brazil. African Journal of Microbiology Research, 5(21), 3542-3545.

[8] Zadeh, L. A. (1973). Outline of a new approach to the analysis of complex systems and decision processes. IEEE Transactions on systems, Man, and Cybernetics, (1), 28-44.

[9] Sarı, M., Murat, Y. Ş., \& Kırabal1, M. (2005). Fuzzy Modeling Approach And Its Applications. Journal of Science and Technology of Dumlupınar University, (009), 77-92.

[10] Atil, H., \& Akilli, A. (2016). Comparison of artificial neural network and K-means for clustering dairy cattle. International Journal of Sustainable Agricultural Management and Informatics, 2(1), 4052.

[11] Gökce, R., Aslanalp, Y., \& Herken, E. N. (2010). Microbiological quality of karin butter, a traditionally manufactured butter from Turkey.

[12] Baykal, N., \& Beyan, T. (2004). Fuzzy logic principles and foundations. Knives Bookstore.

[13] Allahverdi, N.(2020). Fuzzy logic and Applications in Medicine

[14] Yasmeen, S., \& Khan, M. S. (2013). Automated milk preservation system using fuzzy logic system. $J$. Anim. Plant Sci, 23, 1477-1481.

[15] Sivanandam, S. N., Sumathi, S., \& Deepa, S. N. (2007). Introduction to fuzzy logic using MATLAB (Vol. 1). Berlin: Springer.

[16] Elmas, C., \& Controllers, B. M. (2003). Ankara: Seçkin Publishing Industry.
[17] Gorgulu, O. (2007). A research on the theory of fuzzy logic and its use in agriculture. Mustafa Kemal University, Institute of Science and Technology.

[18] De Mol, R. M., \& Woldt, W. E. (2001). Application of fuzzy logic in automated cow status monitoring. Journal of dairy science, 84(2), 400-410.

[19] Baykal, N., \& Beyan, T. (2004). Fuzzy logic principles and foundations. Bıçaklar Bookstore.

[20] Sen, Z. (2001). Fuzzy logic and modeling principles. Bilge Culture and Arts, Istanbul. 